\title{
Introduction to the Special Issue on Fabrication Technologies and Do-It-Yourself Accessibility
}

We are pleased to present this new issue of the TACCESS journal, which contains six articles. The first two articles are part of a special issue on personal fabrication technologies and do-it-yourself accessibility.

The guest editors for this special issue were Daniel Ashbrook (University of Copenhagen), Shaun K. Kane (University of Colorado), and Tom Yeh (University of Colorado), and the supervising editor-in-chief for this issue was Kathleen F. McCoy (University of Delaware).

In the call for submissions to this issue, the guest editors described how personal fabrication technologies such as 3D printers, laser cutters, and computer numerical controlled (CNC) mills present opportunities for end-users to design and create new hardware and interactive devices, including new types of assistive technologies to support people with a range of accessibility needs. Many communities have formed both online and offline to support the creation of accessible technologies for people with disabilities, and people with disabilities have themselves adopted Do-ItYourself (DIY) practices to create assistive technologies to support their own unique needs.

The first article, "Wear it Loud: How and Why Hearing Aid and Cochlear Implant Users Customize Their Devices," (https://doi.org/10.1145/3214382) investigates the customization of hearing aids and cochlear implants by users through an analysis of an online community forum and interviews with stakeholders. The authors discuss the motivations and socio-cultural factors, including self-expression, which influence users' decisions to customize their assistive technology.

The second article, "Autonomous Selection and Printing of 3D Models for People Who Are Blind,” (https://doi.org/10.1145/3241066) presents and evaluates a system to enable people with visual impairments to autonomously search for and print 3D models. Through multiple user studies, the authors investigate the efficacy and accessibility of their system.

We thank the guest editors for their work on this issue, the authors for their excellent submissions, and all of the reviewers for the journal who contributed their time and expertise to this process.

Matt Huenerfauth and Kathleen F. McCoy

Editors-in-Chief

2018 Copyright is held by the owner/author(s).

1936-7228/2018/08-ART12

https://doi.org/10.1145/3242162 